\title{
Damage control surgery for perforated diverticulitis with diffuse peritonitis: saves lives and reduces ostomy
}

\author{
Dario Tartaglia ${ }^{1 *}$ (D), Gianluca Costa ${ }^{2}$, Antonio Camillò ${ }^{1}$, Maurizio Castriconi ${ }^{3}$, Mauro Andreano ${ }^{3}$, Michele Lanza $^{3}$, \\ Pietro Fransvea ${ }^{2}$, Paolo Ruscelli ${ }^{4}$, Massimiliano Rimini ${ }^{4}$, Christian Galatioto ${ }^{1}$ and Massimo Chiarugi ${ }^{1}$
}

\begin{abstract}
Introduction: Over the last decade, damage control surgery (DCS) has been emerging as a feasible alternative for the management of patients with abdominal infection and sepsis. So far, there is no consensus about the role of DCS for acute perforated diverticulitis. In this study, we present the outcome of a multi-institutional series of patients presenting with Hinchey's grade III and IV diverticulitis managed by DCS.

Methods: All the participating centers were tertiary referral hospitals. A total of 34 patients with perforated diverticulitis treated with DCS during the period 2011-2017 were included in the study. During the first laparotomy, a limited resection of the diseased segment was performed followed by lavage and use of negative pressure wound therapy (NPWT). After 24/48 h of resuscitation, patients returned to the operating room for a second look. Mortality, morbidity, and restoration of bowel continuity were the primary outcomes of the study.

Results: There were 15 males (44\%) and 19 females (56\%) with a mean age of 66.9 years (SD \pm 12.7 ). Mean BMI was $28.42 \mathrm{~kg} / \mathrm{m}^{2}$ (SD \pm 3.33 ). Thirteen cases (38\%) were Wasvary's modified Hinchey's stage III, and 21 cases (62\%) Hinchey's stage IV. Mean Mannheim Peritonitis Index (MPI) was 25.12 (SD \pm 6.28$)$. In 22 patients (65\%), ASA score was $\geq$ grade III. Twenty-four patients (71\%) had restoration of bowel continuity, while 10 (29\%) patients had an end colostomy (Hartmann's procedure). Three of these patients received a temporary loop ileostomy. One patient had an anastomotic leak. Mortality rate was $12 \%$. Mean length of hospital stay was 21.9 days. At multivariate analysis, male gender $(p=0.010)$ and MPI $(p=0.034)$ correlated with a high percentage of Hartmann's procedures.

Conclusion: DCS is a feasible procedure for patients with generalized peritonitis secondary to perforated diverticulitis, and it appears to be related to a higher rate of bowel reconstruction. Due to the open abdomen, stay in ICU with prolonged mechanical ventilation is required, but these aggressive measures may be needed by most patients undergoing surgery for perforated diverticulitis, whatever the procedure is done.
\end{abstract}

Keywords: Complicated diverticulitis, Damage control surgery, Observational study

\section{Introduction}

Despite the ongoing progress for resuscitation of septic patients, Hartmann's procedure (HP) is still considered the safest treatment for generalized peritonitis secondary to complicated acute diverticulitis (Hinchey's classification stages III and IV) [1-3]. However, the optimal surgical treatment for generalized peritonitis due to

\footnotetext{
* Correspondence: dario261184@gmail.com

${ }^{1}$ Emergency Surgery Unit, New Santa Chiara Hospital, University of Pisa, Via

Paradisa 2, 56124 Pisa, Italy

Full list of author information is available at the end of the article
}

diverticular perforation remains controversial [4]. Up to half of the patients who underwent HP do not have their stoma reversed as restoration of bowel continuity carries significant morbidity and mortality [5]. To date, the use of resection with primary anastomosis (PA) is a matter of debate; as reported in the literature, PA is substantially equivalent to HP in terms of morbidity, mortality, and length of postoperative stay [6]. PA is often reserved for younger patients with few comorbidities and a lesser degree of peritoneal contamination. Over the last decade, damage control surgery (DCS) has been emerging

(c) The Author(s). 2019 Open Access This article is distributed under the terms of the Creative Commons Attribution 4.0 International License (http://creativecommons.org/licenses/by/4.0/), which permits unrestricted use, distribution, and 
as a valid alternative to $\mathrm{HP}$ and one-stage $\mathrm{PA}$ in patients presenting with severe sepsis caused by purulent or fecal peritonitis in acute diverticulitis. Initially described for the treatment of major abdominal injuries, indications for DCS have subsequently been extended to septic shock, abdominal compartment syndrome, and the impossibility to perform a primary closure. This study aimed to describe the effects of damage control surgery on the outcome of patients with purulent and fecal diverticular peritonitis.

\section{Methods}

\section{Patient selection}

The charts of a series of patients who underwent DCS for purulent or fecal diverticular peritonitis in four Italian institutions during the period 2011-2017 were evaluated. Participating centers were tertiary care referral hospitals (Department of Emergency Surgery, Cisanello University Hospital, Pisa, Italy; Department of General Surgery, Cardarelli Hospital, Napoli, Italy; Sant'Andrea University Hospital, Roma, Italy; Emergency Surgery Unit, Polytechnic University of Marche, Ospedali Riuniti Teaching Hospital, Ancona, Italy). Diverticulitis was staged according to Wasvary's modified Hinchey classification [7]. Inclusion criteria were patients older than 18 years with purulent or fecal peritonitis (Hinchey stage III and IV) secondary to perforated diverticulitis with septic shock and severe grade of peritoneal contamination. The condition of shock was diagnosed according to the parameters of the 3rd International Consensus Definitions for Sepsis and Septic Shock. These are presence of hypotension persisting despite adequate fluid resuscitation and requiring vasopressors with at least one of the following organ failures: kidney failure (creatinine level $>177 \mathrm{mmol} / \mathrm{l}$ or urea level $>167 \mathrm{mmol} / \mathrm{l}$ or oliguria $<20$ $\mathrm{ml} / \mathrm{h}$ ) and pulmonary insufficiency (pO2 $<50 \mathrm{mmHg}$ and $\mathrm{pCO} 2>50 \mathrm{mmHg}$ ) [8]. All patients underwent clinical assessment and a CT scan before the surgical procedure. Exclusion criteria were age older than 90 years and the presence of poor prognosis-associated comorbidities (es. advanced malignancy) or severe limitation of self-sufficiency (neurologic diseases, caregivers' dependence) that a priori favored the choice of an end colostomy.

\section{Surgical procedure}

At laparotomy, once the affected bowel segment was resected and the abdominal cavity copiously irrigated with saline solution, the open abdomen (OA) technique was set up by using a negative pressure wound therapy (NPWT, with or without continuous lavage). The decision to restore continuity or create a terminal colostomy was postponed to a second-look operation, 24-48 h later. Occasionally, at the surgeon's discretion, the $\mathrm{OA}$ was maintained following the second-look procedure if the surgical scenario was believed still contaminated and not safe for bowel reconstruction. In such instances, a fascial mesh was placed in order to avoid fascial retraction of the abdominal wall. A defunctioning ileostomy was performed based on the surgeon's choice when the bowel continuity was re-established. Alternatively, an end colostomy according to Hartmann's procedure was the choice for those patients in which an intestinal anastomosis was judged unsafe.

\section{Data analysis and outcome measures}

Data analysis included age, gender, Body Mass Index (BMI), American Society of Anesthesiologists (ASA) score, Wasvary's modified Hinchey's classification stage III and IV rate, severity of peritonitis according to Mannheim Peritonitis Index [9], type of OA technique performed, mean number of looks performed during $\mathrm{OA}$, and modified $\mathrm{Bj}$ rck classification at II look [10]. Primary outcomes were mortality, overall and specific morbidity according to Clavien and Dindo classification [11], and intestinal anastomosis rate with/without a temporary stoma. Other outcomes included the length of ICU stay, length of total postoperative stay, recurrence of diverticulitis, and late development of an incisional hernia. Follow-up evaluation was based on interval outpatient clinic visit à la demand and/or on a telephone interview.

\section{Statistical analysis}

Quantitative data are expressed as mean or median \pm standard deviation (SD). The qualitative data were elaborated as frequency and percentage. The Mann-Whitney $U$ test was carried out to analyze quantitative variables. Fisher's exact test was performed to study categorical variables. Univariate analysis of age, male gender, BMI, ASA score $>2$, MPI, and Bj rck grade at the II look were performed in order the evaluate a statistical difference in patients presenting with end colostomy versus those with an intestinal anastomosis. Any variable with $p<0.2$ at univariate analysis was entered in a multivariate backward stepwise logistic regression model with Hartmann's procedure as a dependent variable. The statistical analysis was performed using the IBM SPSS software package, version 21.0 for Mac OsX.

\section{Results}

During the period of study, 34 patients underwent DCS for septic shock secondary to purulent or fecal diverticular peritonitis. Mean age was 66.9 years $(\mathrm{SD} \pm 12.7)$ (Table 1). There were 15 males (44\%) and 19 females (56\%). Mean BMI was $28.42 \mathrm{~kg} / \mathrm{m}^{2}(\mathrm{SD} \pm 3.33)$. ASA score was $>2$ in 22 patients (65\%). Based on the severity of the disease, 13 cases (38\%) were classified as 
Table 1 Univariate analysis

\begin{tabular}{|c|c|c|c|c|}
\hline Parameters & Total $(N=34)$ & Anastomosis $(N=24)$ & Hartmann's $(N=10)$ & $p$ value \\
\hline Male gender & $15(44 \%)$ & $7(29 \%)$ & $8(80 \%)$ & 0.010 \\
\hline Mean age $( \pm S D)$ & $66.9( \pm 12.7)$ & $66.25( \pm 11.24)$ & $68.60( \pm 16.25)$ & 0.254 \\
\hline BMI $\left(\mathrm{kg} / \mathrm{m}^{2}\right)( \pm \mathrm{SD})$ & $28.42( \pm 3.33)$ & $27.11( \pm 4.09)$ & $30.10( \pm 5.89)$ & 0.127 \\
\hline ASA score $>\|$ & $22(65 \%)$ & $16(67 \%)$ & $6(60 \%)$ & 0.195 \\
\hline $\mathrm{MPI}( \pm \mathrm{SD})$ & $25.12( \pm 6.28)$ & $23.63( \pm 5.87)$ & $28.70( \pm 6.03)$ & 0.034 \\
\hline Björck grade $\neq 1 \mathrm{~A}$ at $\|$ look & $7(21 \%)$ & $3(13 \%)$ & $4(40 \%)$ & 0.157 \\
\hline \multicolumn{5}{|l|}{ Hinchey's classification: } \\
\hline - Grade III & $13(38 \%)$ & $11(46 \%)$ & $4(40 \%)$ & 1 \\
\hline - Grade IV & $21(62 \%)$ & $13(54 \%$ & $6(60 \%)$ & \\
\hline Type of OA technique adopted: negative pressure wound technique (NPWT) & $34(100 \%)$ & $24(100 \%)$ & $10(100 \%)$ & 1 \\
\hline III look & $7(21 \%)$ & $4(16.6 \%)$ & $3(30 \%)$ & 0.157 \\
\hline Overall morbidity rate* & $14(41 \%)$ & $9(37 \%)$ & $5(50 \%)$ & 0.704 \\
\hline - Grade I & 0 & 0 & 0 & - \\
\hline - Grade II & $6(18 \%)$ & $5(21 \%)$ & $1(10 \%)$ & - \\
\hline - Grade IIla & $1(3 \%)$ & $1(4 \%)$ & 0 & - \\
\hline - Grade IIIb & $5(15 \%)$ & $3(13 \%)$ & $2(20 \%)$ & - \\
\hline - Grade IV & $2(6 \%)$ & 0 & $2(20 \%)$ & - \\
\hline \multicolumn{5}{|l|}{ Cause of reintervention } \\
\hline - Anastomosis dehiscence & $1(3 \%)$ & $1(4 \%)$ & - & 1 \\
\hline - Laparotomy dehiscence & $2(6 \%)$ & $1(4 \%)$ & $1(10 \%)$ & - \\
\hline Mortality rate & $4(12 \%)$ & $1(4 \%)$ & $3(30 \%)$ & 0.066 \\
\hline Mean length of hospital stay ( \pm SD) (days) & $21.9( \pm 16.24)$ & $22.45 \pm 17.74$ & $20.5 \pm 11.72$ & 0.752 \\
\hline
\end{tabular}

*According to the Clavien and Dindo classification

Italics indicate statistical significance

Wasvary's modified Hinchey's stage III, and 21 cases (62\%) as Hinchey's IV. The mean MPI was 25.12 (SD \pm 6.28). A NPWT technique for open abdomen was performed in all patients. In seven cases (21\%), there was the need for a third look for the persistence of peritoneal contamination: four of these had an intestinal anastomosis eventually. The modified Björck classification at II look were $1 \mathrm{~A}=27,1 \mathrm{~B}=3,1 \mathrm{C}=2,2 \mathrm{~A}=0,2 \mathrm{~B}=1,2 \mathrm{C}=1$, $3 \mathrm{~A}=0,3 \mathrm{~B}=0$, and $4=0$.

In 24 cases $(71 \%)$, the intestinal continuity was restored, and in 3 of these (12\%), a protective loop ileostomy was performed. Ten patients had an end colostomy as a result of the DCS. The overall morbidity rate was $41 \%(14 / 34)$. According to the Clavien and Dindo classification, there were 0 grade I $(0 \%), 6$ grade II (18\%), 6 grade III (18\%), and 2 grade IV (6\%). In three cases (9\%), a re-operation was needed: in one case for an anastomotic leak and two cases for dehiscence of the laparotomy wound. In the patient with the bowel leak, the anastomosis was dismantled, and an end colostomy was warranted.

The mean ICU length was 13.98 days ( $\mathrm{SD} \pm 13.47$ ), and the mean postoperative stay was 21.9 days ( $\mathrm{SD} \pm 16.24$ ).
Four deaths $(12 \%)$ were recorded: three patients following a Hartmann's procedure and one after bowel anastomosis $(p=0.067$; odds ratio 3.067 [95\% CI $0.555-$ 16.935]). All deaths were related to the multiorgan failure. Mean follow-up was 47 months $(\mathrm{SD} \pm 35.67)$; all patients with loop ileostomy underwent closure of ileostomy. None of the patients presenting with an end colostomy had a Hartmann's reversal. So far, the incisional hernia developed in 8 out 30 patients (27\%) seen on our patient visit. No recurrence of diverticulitis episodes occurred.

At univariate analysis, male gender $(p=0.010)$ and MPI $(p=0.034)$ correlate with a high percentage of Hartmann's procedures (Table 1). These parameters result at multivariate analysis as predictive factors for an end colostomy creation (Table 2).

\section{Discussion}

Perforated diverticulitis with generalized peritonitis requires immediate surgical intervention. A high percentage of these patients develop severe septic shock with multiorgan dysfunction [12]. Over the last decade, damage control surgery has been emerging as possible 
Table 2 Multivariate analysis

\begin{tabular}{|c|c|c|c|c|c|c|c|c|c|}
\hline & & \multirow[t]{2}{*}{ B } & \multirow[t]{2}{*}{ E.S. } & \multirow[t]{2}{*}{ Wald } & \multirow[t]{2}{*}{ df } & \multirow[t]{2}{*}{ Sig. } & \multirow{2}{*}{$\begin{array}{l}\text { Exp } \\
\text { (B) }\end{array}$} & \multicolumn{2}{|l|}{$95 \% \mathrm{Cl}$} \\
\hline & & & & & & & & Inferior & Superior \\
\hline \multirow[t]{6}{*}{ Step 1} & Male gender & 3.141 & 1.366 & 5.286 & 1 & 0.021 & 23.136 & 1.590 & 336.734 \\
\hline & BMl & 0.162 & 0.156 & 1.080 & 1 & 0.299 & 1.176 & 0.866 & 1.596 \\
\hline & MPI & 0.141 & 0.105 & 1.802 & 1 & 0.179 & 1.151 & 0.937 & 1.414 \\
\hline & Björck grade & 1.614 & 1.527 & 1.117 & 1 & 0.291 & 5.023 & 0.252 & 100.141 \\
\hline & ASA $>2$ & .103 & 1.582 & 0.004 & 1 & 0.948 & 1.109 & 0.050 & 24.647 \\
\hline & Constant & -1.178 & 5.832 & 3.674 & 1 & 0.055 & 0.000 & & \\
\hline \multirow[t]{3}{*}{ Step 4} & Male gender & 2.700 & 1.050 & 6.613 & 1 & 0.010 & 14.881 & 1.901 & 116.509 \\
\hline & MPI & 0.70 & 0.077 & 4.931 & 1 & 0.026 & 1.185 & 1.020 & 1.377 \\
\hline & Constant & -6.750 & 2.336 & 8.349 & 1 & 0.004 & 0.001 & & \\
\hline
\end{tabular}

alternative management of patients with abdominal infection and sepsis. So far, there is no consensus about the role of DCS in acute perforated diverticulitis. Hartmann's procedure remains the therapy of choice in this critical situation in many medical institutions. Indeed, in those patients with pre-existing life-threatening comorbidities, it could be not reasonable to go for a primary anastomosis. However, several studies suggest that the mortality rate is the same for the Hartmann procedure and primary anastomosis $[4,13,14]$.

In a recent randomized multicenter study, Bridoux et al. demonstrate on 102 patients with diverticular peritonitis that overall mortality did not differ significantly between HP (7.7\%) and PA (4\%) and that morbidity for both resection and stoma reversal operations was comparable (39\% HP vs. 44\% PA). Furthermore, they found that at 18 months, $96 \%$ of PA patients with loop ileostomy and $65 \%$ of $\mathrm{HP}$ patients had a stoma reversal. Thus, they concluded that PA with diverting ileostomy is preferable respect to $\mathrm{HP}$ in patients with diverticular peritonitis [6].

Moreover, it has been demonstrated that Hartmann's reversal with the restoration of the bowel continuity is associated with a significant high rate of morbidity (60\%), anastomotic leak (30\%), and mortality (up to 15\%) [15]. Colostomy complications often require additional surgical procedures with increased morbidity. Many patients (20 to $50 \%$ ) may even never have their colostomy reversed because of severe perioperative risks [16-19].

Primary anastomosis has been widely accepted as an alternative to $\mathrm{HP}$ with comparable mortality and a low risk of anastomotic leakage [20-23]. The procedure is often reserved for patients with low-grade comorbidities and less peritoneal contamination [16, 19, 23]. However, a scenario of fecal or purulent peritonitis caused by acute diverticulitis and the presence of septic shock may keep the creation of an anastomosis not feasible or unsafe. In this setting, DCS matches the purpose of obtaining the control of the septic source with the purpose of offering a bowel reconstruction under better abdominal conditions [23].

The recent World Society of Emergency Surgery guidelines about the management of intra-abdominal sepsis state that there is insufficient evidence to advocate for DCS as a general strategy in patients with secondary peritonitis (Recommendation $1 \mathrm{C}$ ). On the other hand, even though with a low grade of recommendation (Recommendation $2 \mathrm{C}$ ), the same guidelines suggest that DCS may be an option in selected significantly physiologically deranged patients with ongoing sepsis [24].

Only a few case series focusing on DCS for perforated diverticulitis are so far reported. Perathoner et al. were the first to describe the combination of emergency laparotomy with the application of abdominal vacuum-assisted closure (V.A.C. ${ }^{\oplus}$ ) to treat patients with generalized peritonitis in 2010 [25]. They analyzed 15 patients who underwent DCS with lavage, limited resection of the diseased colonic segment, VAC, and second-look operation; 9 of them had intestinal continuity restored during a second-look operation, with 1 patient developing anastomotic leakage. More recently, Sohn et al. reported on 58 patients undergone DCS for Hinchey III (81\%) and Hinchey IV (19\%) acute diverticulitis; they recorded a secondary bowel restoration rate of $83 \%$ with a $24 \%$ of loop ileostomy rate. Ten percent of their patients experienced an anastomotic leak that eventually required the creation of a stoma. At the end of the hospital stay, they scored a $50 \%$ rate of patients without a stoma [23]. Kafka-Ritsh et al. reported a series of 51 patients with diverticular peritonitis where the rate of bowel restoration at the second-look operation was $76 \%$ with an $11 \%$ rate of loop ileostomy. Their fistula rate was $13 \%$. [26].

A careful selection of patients that may have benefited from DCS is mandatory in order to avoid overtreatment. It is evident that OA with multiple steps surgery is a risky and costly procedure, and for these reasons, it should not be carried out to merely restore bowel 
continuity. The primary target of the procedure should be to save lives while to avoid a stoma comes as a reasonable consequence of the first. In our study, $68 \%$ of all patients were discharged with a colonic anastomosis. The mortality rate was $12 \%$, slightly higher than data reported in the literature $(9-9.8 \%)[23,26]$. In our cohort, neither fistula formation nor bleeding, that represents an important complication of negative pressure therapy in OA, were observed.

Moreover, a dynamic fascial closure and early removal of the NPWT system allowed for primary closure of the abdominal wall in all patients, although $27 \%$ of patients developed an incisional hernia in the follow-up. Anastomotic leak occurred in one patient (3\%), and an end colostomy managed it at re-operation. At the multivariate analysis, male gender and MPI turned out to be the predictive factors for an end colostomy creation at the II look.

We are fully aware of several limitations affecting the present study. Firstly, it has a relatively low number of enrolled patients, and it cannot be excluded a bias in patients' selection. Moreover, the study is retrospective, and it encompasses a quite large period. Finally, reliable criteria backing the decision to restore bowel continuity or to bail out with an end colostomy at the time of second look are lacking.

\section{Conclusions}

Damage control strategy represents a feasible strategy for patients with generalized peritonitis secondary to perforated diverticulitis. This surgical approach seems to offer a high rate of bowel reconstruction with less stoma, without increasing mortality and morbidity. It requires a stay in ICU with prolonged mechanical ventilation, a hefty price that however these patients should have paid to septic shock independently from the type of surgery. Further randomized, controlled, and comparative studies are needed to achieve significant conclusions.

\section{Abbreviations}

ASA: American Society of Anesthesiologists; BMI: Body mass index;

DCS: Damage control surgery; HP: Hartmann's procedure; ICU: Intensive care unit; NPWT: Negative pressure wound therapy; OA: Open abdomen; PA: Primary anastomosis

\section{Acknowledgements}

Not applicable

\section{Funding}

Not applicable

\section{Availability of data and materials}

The authors state that all data generated or analyzed during this study are included in this published article.

\section{Authors' contributions}

DT, GC, MC, and MC provided the substantial contributions to the study conception and design. AC, MA, ML, PF, PR, and MR made the data acquisition. $D T, G C, C G, M C$, and $M C$ made the substantial contributions to the data analysis and interpretation. DT, GC, and MC drafted the manuscript. All authors read and approved the manuscript.

\section{Ethics approval and consent to participate}

Data were collected as part of routine postoperative follow-up, and all patients provided informed consent for the use of their data for research purposes. The institutional review board approval was therefore not required for this study.

\section{Consent for publication}

Not applicable.

\section{Competing interests}

The authors state that they have no competing interests. The abstract has been presented at the 5th WSES congress by DT. No funding was given to the authors for the presentation.

\section{Publisher's Note}

Springer Nature remains neutral with regard to jurisdictional claims in published maps and institutional affiliations.

\section{Author details}

${ }^{1}$ Emergency Surgery Unit, New Santa Chiara Hospital, University of Pisa, Via Paradisa 2, 56124 Pisa, Italy. Emergency Surgery Unit, Sant'Andrea Teaching Hospital, University Sapienza, Rome, Italy. ${ }^{3}$ Emergency Surgery Unit, Ospedale Cardarelli, Naples, Italy. ${ }^{4}$ Emergency Surgery Unit, Ospedali Riuniti Teaching Hospital, Polytechnic University of Marche, Ancona, Italy.

Received: 8 February 2019 Accepted: 28 March 2019

Published online: 16 April 2019

\section{References}

1. Masoomi H, Buchberg BS, Magno C, et al. Trends in diverticulitis management in the United States from 2002 to 2007. Arch Surg. 2011;146: 400-6.

2. Li D, Baxter NN, McLeod RS, et al. Evolving practice patterns in the management of acute colonic diverticulitis: a population-based analysis. Dis Colon Rectum. 2014;57:1397-405.

3. Hong MK, Tomlin AM, Hayes IP, Skandarajah AR. Operative intervention rates for acute diverticulitis: a multicentre state-wide study. ANZ J Surg. 2015;85:734-8.

4. Cirocchi R, Afshar S, Shaban F, Nascimbeni R, Vettoretto N, Di Saverio S, et al. Perforated sigmoid diverticulitis: Hartmann's procedure or resection with primary anastomosis - a systematic review and meta-analysis of randomized control trials. Tech Coloproctol. 2018;22(10):743-53.

5. Cirocchi R, Trastulli S, Desiderio J, et al. Treatment of Hinchey stage III-IV diverticulitis: a systematic review and meta-analysis. Int J Color Dis. 2013;28: 447-57.

6. Bridoux V, Regimbeau JM, Ouaissi M, Mathonnet M, Mauvais F, Houivet E, Schwarz L, Mege D, Sielezneff I, Sabbagh C, Tuech JJ. Hartmann's procedure or primary anastomosis for generalized peritonitis due to perforated diverticulitis: a prospective multicenter randomized trial (DIVERTI). J Am Coll Surg. 2017;225(6):798-805.

7. Wasvary $\mathrm{H}$, Turfah $\mathrm{F}$, Kadro O, et al. Same hospitalization resection for acute diverticulitis. Am Surg. 1999;65:632-5.

8. Singer M, Deutschman C, Seymour C, Shankar-Hari M, Annane D, Bauer M, et al. The third international consensus definitions for Sepsis and septic shock (Sepsis-3). JAMA. 2016:315(8):801.

9. Linder MM, Wacha H, Feldmann U, Wesch G, Streifensand RA, Gundlach E. The Mannheim peritonitis index. An instrument for the intraoperative prognosis of peritonitis. Chirurg. 1987;58(2):84-92.

10. Björck M, Kirkpatrick AW, Cheatham M, Kaplan M, Leppäniemi A, De Waele JJ. Amended classification of the open abdomen. Scand J Surg. 2016;105(1):5-10.

11. Dindo D, Demartines N, Clavien PA. Classification of surgical complications, a new proposal with evaluation in a cohort of 6336 patients and results of a survey. Ann Surg. 2004;240(2):205-13.

12. Vermeulen J, Akkersdijk GP, Gosselink MP, Hop WC, Mannaerts GH, van der Harst E, Coene PP, Weidema WF, Lange JF. Outcome after emergency surgery for acute perforated diverticulitis in 200 cases. Dig Surg. 2007;24: 361-6. 
13. Zingg U, Pasternak I, Dietrich M, Seifert B, Oertli D, Metzger U. Primary anastomosis vs. Hartmann's procedure in patients undergoing emergency left colectomy for perforated diverticulitis. Color Dis. 2010;12:54-60.

14. Krukowski ZH, Matheson NA. Emergency surgery for diverticular disease complicated by generalized and fecal peritonitis: a review. Br J Surg. 1984; 71:921-7.

15. Constantinides VA, Tekkis PP, Athanasiou T, Aziz O, Purkayastha S, Remzi FH, Fazio VW, Aydin N, Darzi A, Senapati A. Primary resection with anastomosis vs. Hartmann's procedure in nonelective surgery for acute colonic diverticulitis: a systematic review. Dis Colon Rectum. 2006;49:966-81.

16. Ferzoco LB, Raptopoulos V, Silen W. Acute diverticulitis. N Engl J Med. 1998; 338:1521-6.

17. Salem L, Flum DR. Primary anastomosis or Hartmann's procedure for patients with diverticular peritonitis? A systematic review. Dis Colon Rectum. 2004:47:1953-64.

18. Seetharam S, Paige J, Horgan PG. Impact of socioeconomic deprivation and primary pathology on the rate of reversal of Hartmann's procedure. Am J Surg. 2003;186:154-7.

19. Chouillard E, Maggiori L, Ata T, Jarbaoui S, Rivkine E, Benhaim L, Ghiles E, Etienne JC, Fingerhut A. Laparoscopic two-stage left colonic resection for patients with peritonitis caused by acute diverticulitis. Dis Colon Rectum. 2007:50:1157-63.

20. Taylor CJ, Layani L, Ghusn MA, White SI. Perforated diverticulitis managed by laparoscopic lavage. ANZ J Surg. 2006;76:962-5.

21. Favuzza J, Friel JC, Kelly JJ, Perugini R, Counihan TC. Benefits of peritoneal lavage for complicated sigmoid diverticulitis. Int J Color Dis. 2009;24:797-801.

22. Franklin ME Jr, Dorman JP, Jacobs M, Plasencia G. Is laparoscopic surgery applicable to complicated colonic diverticular disease? Surg Endosc. 1997; 11:1021-5.

23. Sohn M, lesalnieks I, Agha A, Steiner P, Hochrein A, Pratschke J, Ritschl P, Aigner F. Perforated diverticulitis with generalized peritonitis: low stoma rate using a "damage control strategy". World J Surg. 2018;42(10):31893195.

24. Sartelli M, Catena F, Abu-Zidan FM, Ansaloni L, Biffl WL, Boermeester MA, Ceresoli M, Chiara O, Coccolini F, De Waele JJ, Di Saverio S, Eckmann C, Fraga GP, Giannella M, Girardis M, Griffiths EA, Kashuk J, Kirkpatrick AW, Khokha V, Kluger Y, Labricciosa FM, Leppaniemi A, Maier RV, May AK, Malangoni M, Martin-Loeches I, Mazuski J, Montravers P, Peitzman A, Pereira BM, Reis T, Sakakushev B, Sganga G, Soreide K, Sugrue M, Ulrych J, Vincent $J L$, Viale P, Moore EE. Management of intra-abdominal infections: recommendations by the WSES 2016 consensus conference. World J Emerg Surg. 2017 May 4;12:22.

25. Perathoner A, Klaus A, Mühlmann G, Oberwalder M, Margreiter R, KafkaRitsch R. Damage control with abdominal vacuum therapy (VAC) to manage perforated diverticulitis with advanced generalized peritonitis-a proof of concept. Int J Color Dis. 2010;25(6):767-774.

26. Kafka-Ritsch R, Birkfellner F, Perathoner A, Raab H, Nehoda H, Pratschke J, Zitt M. Damage control surgery with abdominal vacuum and delayed bowel reconstruction in patients with perforated diverticulitis Hinchey III/IV. J Gastrointest Surg. 2012;16(10):1915-22.

Ready to submit your research? Choose BMC and benefit from:

- fast, convenient online submission

- thorough peer review by experienced researchers in your field

- rapid publication on acceptance

- support for research data, including large and complex data types

- gold Open Access which fosters wider collaboration and increased citations

- maximum visibility for your research: over $100 \mathrm{M}$ website views per year

At BMC, research is always in progress.

Learn more biomedcentral.com/submissions 